\title{
Histopathological and Haematological Effects of Mosquito Coil Smoke on Lungs - An Experimental Study on Albino Rats
}

\author{
Masooma Syed ${ }^{1}$, Kamaldeep Singh Balowria ${ }^{2}$, Sheikh Tousia ${ }^{3}$, Nusrat Jabeen ${ }^{4}$, Nafis Ahmad Faruqi ${ }^{5}$ \\ ${ }^{1}$ Senior Resident, Department of Anatomy, J.N.M.C, Aligarh Muslim University, Aligarh, ${ }^{2}$ MD Anatomy, Medical Officer, PHC Bhalla Doda, ${ }^{3}$ MD Anatomy, \\ ${ }^{4}$ M.S Anatomy,Associate Professor,Post Graduate Department of Anatomy, GMC Jammu, ${ }^{5}$ M.S Anatomy, Professor, Department of Anatomy, J.N.M.C, \\ Aligarh Muslim University, Aligarh.
}

\section{Abstract}

Introduction: Mosquito coils are the most preferred anti-mosquito products in many households of Asian countries like India. Short-term exposure to allethrin has been reported to cause toxic effects on respiratory system. Subjects and Methods: Thirty albino rats were divided into five groups (A, B, C, D, and E) of six animals each. Except group A (Control) rest (Group B-E) were exposed to mosquito coil smoke for 4, 6, 8 and 10 weeks respectively. Blood from all the animals was processed to estimate TLC (Total leucocyte count) and results thus attained were analysed using one-way ANOVA test. Rats were sacrificed to procure lung tissue, which was processed by paraffin embedding to obtain haematoxylin and Eosin stained sections. Results: There was significant increase ( $p$ value, 0.001) in TLC in all experimental groups compared to control ones. Conclusion: Degenerative changes were obtained in lung tissue of all experimental rats with maximum effect in group Adequate measures should be taken to ensure minimal exposure to coil smoke during domestic use.

Keywords: Mosquito coil, histopathology, haematology, rats, experimental study.

Corresponding Author: Dr. Sheikh Tousia, MD Anatomy, Srinagar, Jammu and Kashmir.

Received: March 2019

Accepted: March 2019

\section{Introduction}

Mosquitoes have long been identified as the main vectors of many human diseases. There were around 0.67 million cases of malaria, with 84 million related deaths in the year 2017 till the month of September in India. ${ }^{[1]}$ Mosquito coils are the most preferred anti-mosquito products in many households of Asian countries like India.

The most common active ingredients in mosquito coils are pyrethroids that are effective against many genera of mosquitoes. $^{[2]}$ Insecticides vaporize with smoke and immobilize mosquitoes. The combustion of the remaining materials generates large amounts of sub-micrometre particles and gaseous pollutants.

These particles may reach and coat the lower respiratory tract along with wide range of organic compounds including polycyclic hydrocarbons and formaldehyde. Important association of polycyclic aromatic hydrocarbons, fine particles and formaldehyde with lung cancer has been suggested. ${ }^{[3]}$

Short-term exposure to bioallethrin has been reported to cause irritation of eyes, skin and respiratory tract along with neurotoxic effects. ${ }^{[4]}$

Lung damage evident by interstitial accumulations, pulmonary oedema and emphysema in exposed rats along with intracellular accumulations and severe sinusoidal congestion of liver cells was noted. ${ }^{[5]}$

In the present study we intend to do a detailed investigation into the histopathological alteration in lungs, kidneys and hematological-indices in rats induced due to prolonged exposure to mosquito coil smoke. As substantial data is not available on the effects of mosquito coils containing d-trans allethrin, we have carried out the study using mosquito repellent coil containing $0.1 \% \mathrm{w} / \mathrm{w}$ of $\mathrm{d}$-trans allethrin.

\section{Subjects and Methods}

The present study was carried out on 30 albino rats of Wistar strain of both sexes. The rats were procured from the "Central Animal House" of Government Medical College, Jammu.

The clearance for use of animals was obtained from "Institutional Ethics Committee" constituted for this purpose.

The animals were divided into 5 main groups (A, B, C, D, and $\mathrm{E}$ ) as follows:

Table 1: Division of animals into 5 groups (A, B, C, D, and E)
\begin{tabular}{|l|l|l|}
\hline Group & Types & Specimen numbers \\
\hline A & Control group & 6 \\
\hline B & Experimental group & 6 \\
\hline C & Experimental group & 6 \\
\hline D & Experimental group & 6 \\
\hline E & Experimental group & 6 \\
\hline
\end{tabular}

As per the guidelines laid down by the "Committee for the 
Purpose of Control and Supervision of Experiment on Animals, (CPCSEA)", the animals were housed in propylene cages of dimensions $44 \times 28.6 \times 30 \mathrm{~cm} 3$, which were placed in a room of size $10 \times 12$ sq. ft. with cross ventilation and facility of fan, where they were acclimatized for two weeks under standard laboratory condition (12 hour light and 12 hour darkness, temperature at $25 \pm 1^{\circ} \mathrm{C}$ ), with ad libitum access to food and water.

\section{Exposure of the rats}

The animals were exposed to mosquito coil smoke for eight hours a day (average period of time that humans sleeps in a day) using mosquito repellent coil brand containing $0.1 \%$ w/w of d-trans allethrin. The mosquito coil was placed at a distance of $30 \mathrm{~cm}$ from the cage.

Table 2: Details of exposure of rats to mosquito coil smoke

\begin{tabular}{|c|c|}
\hline Table 2: Details of exposure of rats to mosquito coil smoke \\
\hline Group & Exposure \\
\hline Group A & Unexposed to coil smoke. \\
\hline Group B & Exposed for 4 weeks \\
\hline Group C & Exposed for 6 weeks \\
\hline Group D & Exposed for 8 weeks \\
\hline Group E & Exposed for 10 weeks \\
\hline
\end{tabular}

\section{Collection of Blood}

At the end of exposure period blood was collected from both control and experimental rats using the retro-orbital procedure, and sent for haematological investigation (TLC). Results were analysed using one-way ANOVA test.

\section{Dissection out the lungs:}

Each rat was placed in a beaker containing chloroform soaked cotton. A lid was placed over the beaker for about 56 minutes to sacrifice the rats. The sacrificed rats were laid supine on the dissecting tray. A cut was given on both sides of sternum at the costo-chondral junction and the thoracic cage was opened by reflecting the sternum upwards to visualise the heart and the lungs. Each lung was separated out by cutting at the hilum; lungs were placed in a fixative, the composition of which was: ${ }^{[6]}$

I. Formalin: $100 \mathrm{~m}$

II. Tap water: $900 \mathrm{~m}$

III. Sodium chloride: $8.5 \mathrm{gms}$

Sections of $8 \mu \mathrm{m}$ were obtained by paraffin embedding technique and stained with haematoxylin and eosin.

\section{Result}

\section{Haematological Indices}

The total leucocyte count (TLC) was increased in all exposed groups, and the difference was significant $(\mathrm{p}<0.001)$ when compared to the control group.

Table 3: Comparison based on TLC among control and experimental groups

\begin{tabular}{|c|c|c|c|c|}
\hline Groups & Mean \pm SD & Range & Comparison & P-value \\
\hline A & $9.08 \pm 1.11$ & $7.5-10.4$ & - & - \\
\hline B & $13.52 \pm 1.93$ & $11.1-16.5$ & A vs B & $0.007^{*}$ \\
\hline C & $20.78 \pm 2.92$ & $16.9-24$ & A vs C & $<0.001^{*}$ \\
\hline D & $23.07 \pm 2.57$ & $19.5-26.2$ & A vs D & $<0.001^{*}$ \\
\hline E & $30.55 \pm 2.08$ & $27.5-33.1$ & A vs E & $<0.001^{*}$ \\
\hline
\end{tabular}

\section{Normal Rat Lung (Group A)}

Respiratory part of rat's lung consists of respiratory bronchioles, alveolar ducts, alveolar sacs and alveoli. The intrapulmonary bronchus had several cartilage plates located in close proximity to each other. The epithelium was pseudostratified columnar ciliated with goblet cells. The rest of wall consisted of thin lamina propria, an arrow layer of smooth muscle and submucosa with scattered bronchial glands, hyaline cartilage plates and adventitia.

Terminal bronchioles had wavy mucosal lining with ciliated columnar epithelium, a thin layer of smooth muscle and adventitia. The respiratory bronchioles had direct connection with the alveolar ducts and alveoli. The epithelium was low columnar or cuboidal. Each distal respiratory bronchiole terminated into several alveolar ducts. The cluster of alveoli that open into alveolar duct is called an alveolar sac.

The alveoli were lined by simple squamous epithelium and shared common interalveolar septa between them. Located in the thin septum were capillary plexus supported by connective tissue.

\section{Group B}

Sections examined showed mixed inflammatory response in the interstitium, consisting of acute and chronic inflammation. There was mild vascular congestion and interstitial edema. Bronchial epithelial lining was normal and small amount of lymphocytic infiltration was seen around the bronchioles. Alveoli appeared normal with normal intact interalveolar septa and no proteinaceous material was seen in the alveoli.

\section{Group C}

Lungs of rats exposed to mosquito coil smoke for6 weeks showed moderate chronic lymphocytic infiltration in the interstitium. There was marked vascular congestion in the interstitium with mild edema. Bronchial epithelial lining was normal with increased lymphocytic infiltration around the bronchioles. Perivascular lymphatic aggregation was also reported. Alveoli were dilated with emphysematous changes.

\section{Group D}

Sections of lung of rats exposed to mosquito coil smoke for a period of 8 weeks showed perivascular lymphoid aggregate formation. There was peribronchial lymphoid hyperplasia and chronic interstitial inflammation. Interstitial congestion was also observed. The lining of respiratory epithelium was normal. The alveoli showed emphysematous changes, infiltration was seen in the alveolar septa as well. There was no proteinaceous exudate in the alveoli.

\section{Group E}

Lungs of rats exposed to coil smoke for 10 weeks showed dense peribronchial and perivascular lymphoid aggregate formation. The alveolar septa were thinned out and alveolar spaces were abnormally widened. There was decrease in the capillary bed. Some areas showed intra-alveolar infiltration and fibrinous exudates, with areas of central necrosis, features consistent with Bronchopneumonia There were desquamation of the bronchial epithelial lining and the bronchiolar lumen was filled with exudates. 
Syed et al; Effects of Masquita Cail Smake an Lungs of Rat

\begin{tabular}{|c|c|c|c|c|c|}
\hline Table 4: Light microscopic changes in lungs exposed to mosquito coil smoke. & Group C & Group D & Group E \\
\hline Changes & Group A & Group B & Normal & Disrupted, emphysematous & Emphysematous \\
\hline Alveoli & Normal & Normal & Absent & Absent & Mresent \\
\hline Exudates & Absent & Absent & Mild & Moderate & Moderate \\
\hline $\begin{array}{c}\text { Peribronchial } \\
\text { inflammation }\end{array}$ & Absent & $\begin{array}{c}\text { Mixed } \\
\text { infiltration } \\
\text { inflammation }\end{array}$ & $\begin{array}{c}\text { Chronic infiltration } \\
\text { with lymphoid } \\
\text { aggregates }\end{array}$ & $\begin{array}{c}\text { Chronic infiltration with } \\
\text { lymphoid aggregates }\end{array}$ & Lymphoid aggregates \\
\hline Blood vessels & Normal & Congestion & Marked congestion & Congestion & Congestion \\
\hline
\end{tabular}

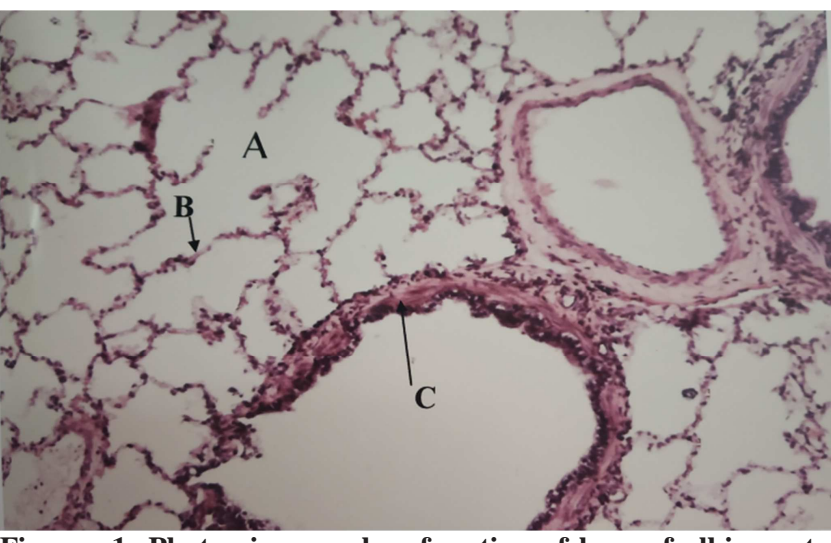

Figgure 1: Photomicrography of section of lung of albino rats of control group showing normal alveoli (A), intact alveolar septum (B) and bronchiole (C). (H\&E Stain $100 \mathrm{X}$ )

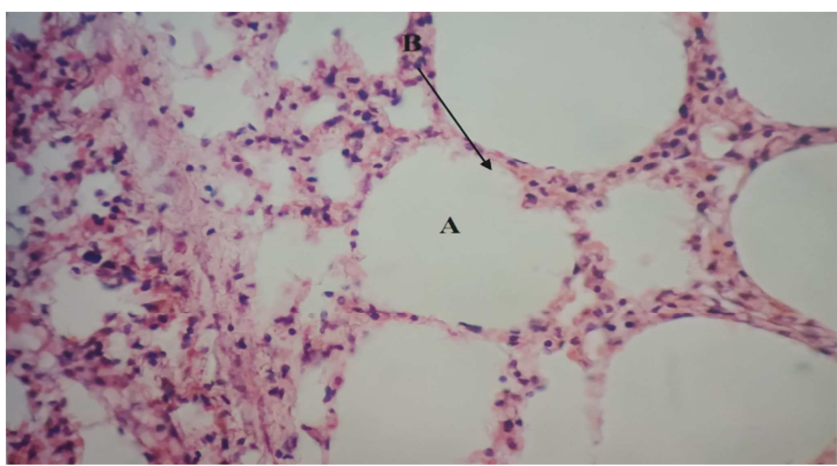

Figure 2: Photomicrography of section of lung of albino rats of control group showing normal alveoli (A) and intact alveolar septum (B). (H\&E Stain $400 \mathrm{X}$ )

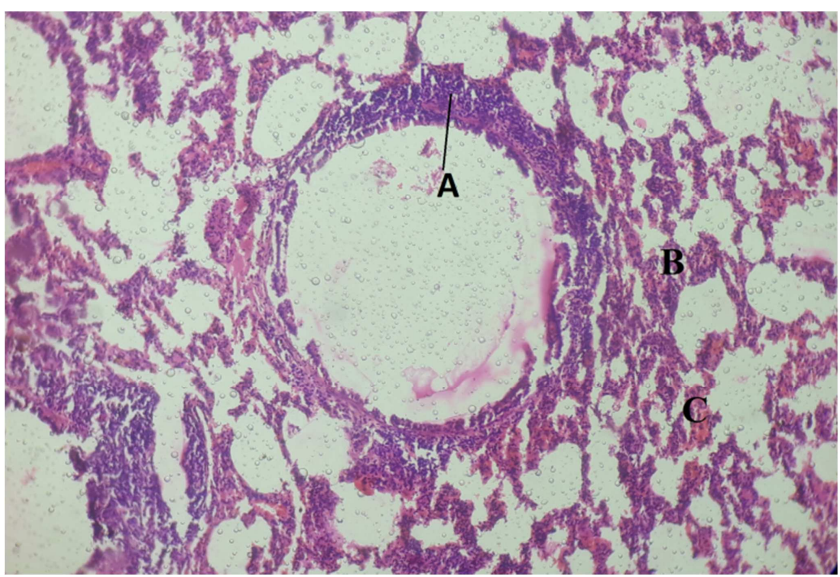

Figure 3: Photomicrography of section of lung of albino rats after 4 weeks of exposure to mosquito coil smoke showing, peribronchial inflammation (A), interstitial inflammation (B) and congestion $(\mathrm{C})$. (H\&E Stain $100 \mathrm{X})$

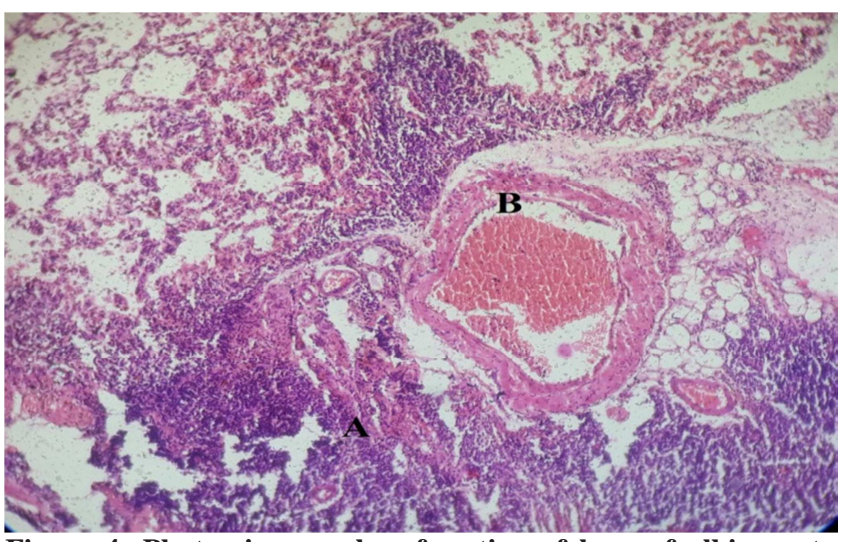

Figure 4: Photomicrography of section of lung of albino rats after 6 weeks of exposure to mosquito coil smoke showing perivascular lymphoid aggregate (A) and vascular congestion (B). (H\&E Stain $100 \mathrm{X})$

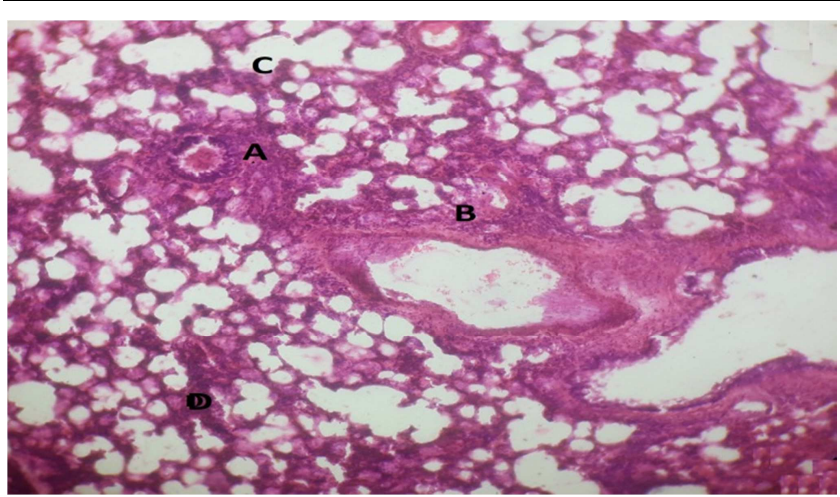

Figure 5: Photomicrography of section of lung of albino rats after 8 weeks of exposure to mosquito coil smoke showing peribronchiolar lymphocytic infiltrate (A), perivascular chronic inflammation (B), focal emphysematous changes (C) and interstitial inflammation (D). (H\&E Stain $100 \mathrm{X}$ )

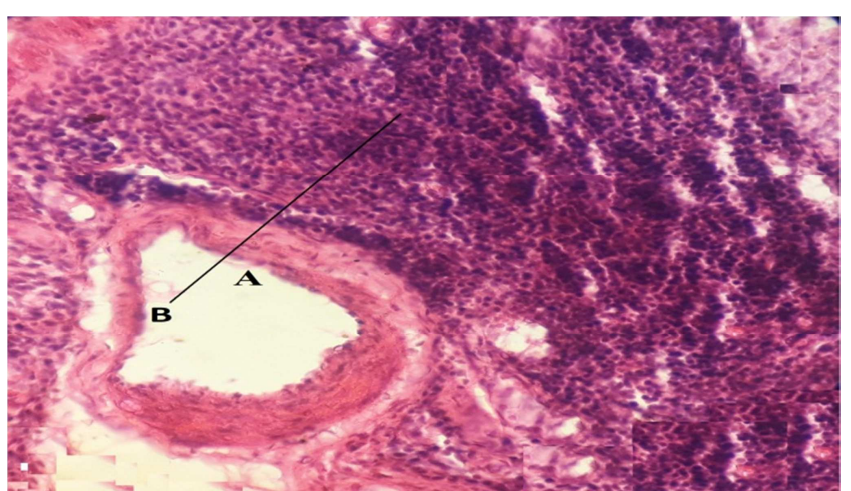

Figure 6: Photomicrography of section of lung of albino rats after 8 weeks of exposure to mosquito coil smoke showing vessel (A) and perivascular lymphoid aggregate (B). (H\&E Stain $400 \mathrm{X}$ ) 


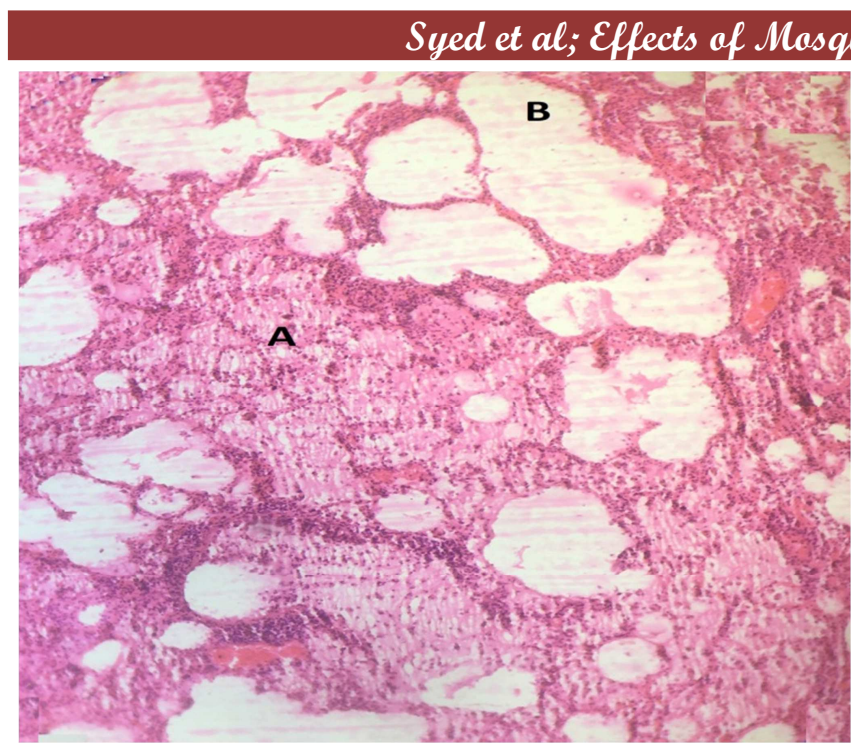

Figure 7: Photomicrography of section of lung of albino rats after 10 weeks of exposure to mosquito coil smoke showing intra alveolar proteinaceous material and acute inflammation (A) and emphysematous changes (B). (H\&E Stain $400 \mathrm{X}$ )

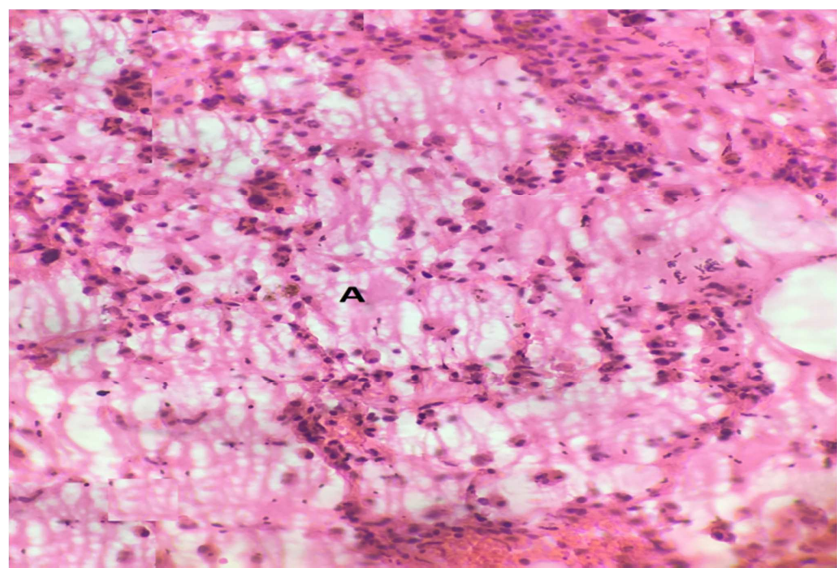

Figure 8: Photomicrography of section of lung of albino rats after 10 weeks of exposure to mosquito coil smoke showing bronchopneumonia (A). (H\&E Stain $400 \mathrm{X}$ )

\section{Discussion}

Ayorinde et al. (2014), ${ }^{[7]}$ showed significant increase in the total leucocyte count $(23.4 \pm 0.42 \mathrm{mg} / \mathrm{dl})$ in the experimental animals at 4 weeks when compared with the control group $(14.55 \pm 0.07 \mathrm{mg} / \mathrm{dl})$, which is in accordance with the present study but at the same time they showed no significant change in the platelet count, which is in discordance with the present study.

Similar variations in the leucocyte count were documented by a previous study by Garba et al. $(2007),{ }^{[8]}$ reported a significant increase in total leucocyte count in rats exposed to mosquito coil smoke for 28 days (4 weeks). Idowu et al. (2013), ${ }^{[9]}$ demonstrated substantial increase in total leucocyte count with no significant change in platelet count, which is in accordance with the present study. Total leucocyte count was reported to be insignificantly increased with an insignificant decrease in the platelet count by Saka et al. (2011), ${ }^{[10]}$ in animal exposed for 3 weeks which was not in favour of the present study.
Cail Smake on Lungs of Rat

Pauluhn and Mohr (2006), ${ }^{[1]}$ showed no changes in haematological parameters even after exposure of 13 weeks, which is not in favour of present study.

Histopathological effects of mosquito coil smoke on lung tissue in the present study included interstitial edema, vascular congestion and interstitial inflammation that was initially mixed and then became chronic with increased weeks of exposure. Alveolar dilatation and thinning out of septa finally leading into emphysema starting from 6 weeks of exposure were also reported. The results are in concordance with study done by Liu and Sun (1988) ${ }^{[12]}$ who documented emphysema, increased alveolar macrophages in the alveolar spaces and neutrophilic infiltration in animals exposed for a period of 8 weeks.

In the present study, increase in the perivascular and peribronchial lymphoid aggregation and vascular congestion were observed, which were more marked in rats exposed for 10 weeks. The rats at maximum weeks of exposure also showed decreased capillary bed, intra alveolar eosinophilic material and neutrophil infiltration suggestive of bronchopneumonia. Idowu et al. (2013) ${ }^{[13]}$ also documented peribronchial lymphoid hyperplasia, vascular congestion and pulmonary edema at 16 weeks of exposure, which favours our study. Okine LKN et al. (2004), ${ }^{[14]}$ reported thickening of bronchiolar epithelial wall, consolidation in alveoli with signs of pulmonary edema, emphysema and bronchopneumonia after 6 weeks of exposure, in concordance with our study, that also shows features of bronchopneumonia and emphysema in exposed rats.

Taiwo (2008), ${ }^{[15]}$ documented pneumonia in exposed rats that is consistent with our findings but they also reported thrombosis, vasculitis and anthracosis that were not documented in our study. Septal thickening, consolidation and thickening of bronchiolar epithelial wall were also reported by Ayorinde et al. (2014), ${ }^{[16]}$ that are in concordance with our study. Thus it can be stated that mosquito coil smoke induces lung damage in exposed animals.

\section{Conclusion}

The coil smoke can be toxic for humans as well and general masses should be made aware about the possible hazards of the over-use of mosquito coils. Adequate measures should be taken to ensure minimal exposure to coil smoke during domestic use.

\section{References}

1. National vector borne disease control programme, annual report 2016-2017.

2. Lukwa $\mathrm{N}$ and Chandiwana SK. Efficacy of Mosquito Coil Containing $0.3 \%$ and $0.4 \%$ Pyrethrin Against An. Gambiae Sensu Lato Mosquitoes. Cent Afr J Med.1998;44(4):104-107.

3. Fawcett TA, Moon RE, Fracica PJ et al. Warehouse workers' headache. Carbon monoxide poisoning from propane-fueled forklifts. J Occup Med. 1992; 34(1):12-15.

4. AlamZ,Mohsin A, Khan E et al. Neurohistological Study on the Effect of Prallethrin Vapours on Spinal Cord of Albino Rat. J AnatSci.2013;21(2):19-23.

5. Idowu ET, Aimufua OJ, Ejovwoke YO et al. Toxicological Effects of Prolonged and Intense use of Mosquito Coil Emission 


\section{Syed et al; Effects of Masquita Cail Smake an Lungs of Rat}

in Rats and its Implications on Malaria Control. Int J Trop Biol.2013; 61 (3): 1463-1473.

6. Drury RAB, Wallington EA. General Staining Procedures, Carleton's Histological Techniques, 5th edition. New York: Oxford University Press; 1980. p 125-150.

7. Ayorinde AF, Oboh BO, Otubanjo OA et al. Some Toxicological Effects of a Mosquito Repellent in Lagos State, Nigeria. Res J Environ Toxicol.2014;8(1);46-52.

8. Garba SH, Shehu MM, Adelaiye AB. Toxicological Effects of Inhaled Mosquito Coil Smoke on the Rat Spleen: A Haematological and Histological Study. J Med Sci. 2007; 7(1): 94-99.

9. Idowu ET, Aimufua OJ, Ejovwoke YO et al. Toxicological Effects of Prolonged and Intense use of Mosquito Coil Emission in Rats and its Implications on Malaria Control. Int $\mathrm{J}$ Trop Biol.2013; 61 (3): 1463-1473.

10. Saka WA, Akhigbe RE, Azeez OM et al. Effects of Pyrethroid Insecticide Exposure on Haematological and Haemostatic Profiles in Rats. Pak J Biol Sci.2011;14(22):1024-1027.

11. Pauluhn J and Mohr U. Mosquito Coil Smoke Inhalation Toxicity.
Part II: Subchronic Nose - Only Inhalation Study In Rats. J Appl Toxicol. 2006; 26(3):279-292.

12. Liu WK and Sun SE. Ultrastructural Changes of Tracheal Epithelium and Alveolar Macrophages of Rats Exposed to Mosquito Coil Smoke. Toxicol Lett. 1988; 41(2):145-157.

13. Idowu ET, Aimufua OJ, Ejovwoke YO et al. Toxicological Effects of Prolonged and Intense use of Mosquito Coil Emission in Rats and its Implications on Malaria Control. Int J Trop Biol.2013; 61 (3): 1463-1473.

14. Okine LKN, Nyarko AK, Armah GE et al. Adverse Effects of Mosquito Coil Smoke on Lung, Liver and Certain Drug Metabolizing Enzymes in Male Wistar Albino Rats. Ghana Med J.2004; 38(3): 89-95.

15. Taiwo VO, Nwagbara ND, Suleiman R et al. Clinical Signs and Organ Pathology in Rats Exposed to Graded Doses of Pyrethroids-Containing Mosquito Coil Smoke and Aerosolized Insecticidal Sprays. Afr J Biomed Res.2008; 11(1): 97- 104

16. Ayorinde AF, Oboh BO, Otubanjo OA et al. Some Toxicological Effects of a Mosquito Repellent in Lagos State, Nigeria. Res J Environ Toxicol.2014;8(1);46-52.

Copyright: ( ) the author(s), publisher. Academia Anatomica International is an Official Publication of "Society for Health Care \& Research Development". It is an open-access article distributed under the terms of the Creative Commons Attribution Non-Commercial License, which permits unrestricted non-commercial use, distribution, and reproduction in any medium, provided the original work is properly cited.

How to cite this article: Syed M, Balowria KS, Tousia S, Jabeen N, Faruqi NA. Histopathological and Haematological Effects of Mosquito Coil Smoke on Lungs - An Experimental Study on Albino Rats. Acad. Anat. Int. 2019;5(1):54-58.

DOI: dx.doi.org/10.21276/aanat.2019.5.1.12

Source of Support: Nil, Conflict of Interest: None declared. 